\title{
Specific changes in skeletal muscle myosin heavy chain composition in cardiac failure: differences compared with disuse atrophy as assessed on microbiopsies by high resolution electrophoresis
}

\author{
G Vescovo, F Serafini, L Facchin, P Tenderini, U Carraro, L Dalla Libera, C Catani, \\ G B Ambrosio
}

\begin{abstract}
Objective-In congestive heart failure (CHF) the skeletal muscle of the lower limbs develops a myopathy with atrophy and shift from the slow type to the fast type fibres. The aim was to test the hypothesis that this myopathy is specific and not simply related to detraining, by comparing patients with different degrees of CHF with patients with severe muscle atrophy due to disuse.

Design-Case-control study involving 50-150 $\mu \mathrm{g}$ needle biopsies of the gastrocnemius muscle. By an electrophoretic micromethod, the three isoforms of myosin heavy chains (MHC) were separated.
\end{abstract}

Patients-Five patients restricted to bed for more than one year because of stroke with disuse atrophy and normal ventricular function, and 19 with CHF were studied. There were seven age matched controls.

Main outcome measures-The percentage of MHC1 (slow isoform), MHC2a (fast oxidative), and MHC2b (fast glycolytic) was determined by densitometric scan and correlated with indices of severity of cardiac failure.

Results-Ejection fraction was $42 \cdot 5$ (SD $15 \cdot 2) \%$ in CHF, $59.5(1.0) \%$ in disuse atrophy and $60.3(1.4) \%$ in controls $(P<0.001 v$ both). The degree of muscle atrophy as calculated by the body mass index/gastrocnemius cross sectional area, showed a profound degree of atrophy in patients with muscle disuse $[0.94(0.39)]$. This was worse than in the controls $[4 \cdot 27(0 \cdot 16), P<$ $0.0005]$ and the CHF patients $[2.60(1 \cdot 10)$, $P<0.005]$. Atrophy in CHF patients was also greater than in controls $(P<0.005)$. MHC1 was lower in CHF than in disuse atrophy $[51.83(15.04) v 84.5(17.04), P<$ $0.01]$ while MHC2b was higher [23.5 (7.4) $v 7 \cdot 25$ (7.92), $\mathbf{P}<0.001]$. There was a similar trend for MHC2a [24.83 (15.01) $v$ 8.25 $(9 \cdot 12), P<0.05]$. Within the CHF group there was a positive correlation between NYHA class and MHC2a $(r=0.47, P<$ $0.05)$ and MHC2b $(r=0.55, P<0.01)$ and a negative correlation between NYHA class and MHC1 $(r=-0.74, P<0.001)$. Similarly, significant correlations were found for ejection fraction, diuretic consumption score, exercise test tolerance, and degree of muscle atrophy.

Conclusions-The CHF myopathy appears to be specific and not related to detraining. The magnitude of $\mathrm{MCH}$ redistribution correlates with the severity of the disease. The electrophoretic micromethod used is very sensitive and reproducible. Biopsies are so well tolerated that can be repeated frequently, allowing thorough follow up.

(Heart 1996;76:337-343)

Keywords: congestive heart failure; skeletal muscle myopathy; myosin heavy chains; microbiopsies

In congestive heart failure (CHF) lower limb skeletal muscle performance is disordered and this can at least in part explain symptoms such as fatigue and shortness of breath. ${ }^{1}$ Lipkin et al ${ }^{2}$ initially suggested that quadriceps femoris muscle strength is reduced because of loss of skeletal muscle bulk, although the mean force per unit area was within the normal range. ${ }^{1-3}$ Lipkin et $a l^{2}$ showed in quadriceps muscle biopsies a shift towards type II fibres with presence of atrophic fibres. Mancini et $a l^{4}$ reported a shift toward type IIb fibres and atrophy of type IIa in the gastrocnemius muscle. A reduction of type I and a relative increase of IIb was found by Sullivan $e t a l^{7}$ and Drexler et $a l^{6}$ in needle biopsies from vastus lateralis. Mitochondrial abnormalities also contribute to the myopathy of CHF. ${ }^{6}$ Whether these changes in skeletal muscle composition are due to deconditioning induced atrophy, as suggested by several investigators, ${ }^{7-9}$ or represent a specific myopathy is not clear yet. We tested the hypothesis that CHF myopathy is characterised by intrinsic abnormalities by comparing the skeletal muscle myosin heavy chain (MHC) composition in patients with CHF with that of control subjects and of patients with severe disuse atrophy. The study was carried out on fine needle biopsies taken from the gastrocnemius. The three skeletal muscle MHC isoforms, namely the slow $\mathrm{MHC1}$ isomyosin, the MHC2a (fast oxidative), and the MHC2b (fast glycolytic), were separated using a high resolution electrophoretic micromethod devised in our laboratories. 


\section{Methods}

\section{PATIENTS}

Nineteen patients with CHF (10 males, nine females) (nine with dilated cardiomyopathy, four with hypertensive heart disease, and six with ischaemic heart disease) were studied. These were all patients whose diagnosis was established by means of clinical history, ECG, exercise test, echocardiography, and coronary angiogram. We also studied five patients (three males, two females) with disuse atrophy who had been restricted in bed for more that one year because of stroke and in whom a rehabilitation programme was unsuccessful. These all were normotensive (BP $\leqslant 140 / 95 \mathrm{~mm} \mathrm{Hg}$ ), had normal cardiac function (ejection fraction $\geqslant 60 \%$ ), and had no cross sectional echocardiographic and echo-Doppler cardiac abnormalities. Seven healthy volunteers (four males, three females) with normal medical history, physical examination, normal blood pressure values, ECG, echocardiography, and exercise test tolerance were used as controls. In all the patients the presence of major blood flow abnormalities in the lower limbs was excluded by a Winsor (ankle/brachial) index of $\geqslant 1$.

\section{SKELETAL MUSCLE BIOPSY}

Skeletal muscle biopsies were taken from the gastrocnemius muscle using a $17 \mathrm{G}$ Histo-Cut soft tissue disposable Menghini needle (Sterylab, Milan, Italy). From each specimen, between 50 and $150 \mu \mathrm{g}$ of tissue were obtained. The specimen was immediately frozen in liquid nitrogen and kept in a $-80^{\circ} \mathrm{C}$ fridge until processed. In patients with disuse atrophy biopsies were taken from the nonparetic leg in order to avoid muscle hypertonicity. No anaesthesia was employed.

Informed consent was obtained in all the patients.

\section{CARDIOTHORACIC RATIO}

Cardiothoracic ratio was calculated in each patient from routine chest $x$ ray.

\section{EXERCISE TOLERANCE TEST}

All the patients with CHF and the normal subjects underwent a treadmill exercise test according to a modified Naughton protocol. The protocol envisaged seven stages of three min each at a fixed speed of $3 \mathrm{~km} / \mathrm{h}$ starting from $0 \%$ grade (stage 0 ) with increments of $3.5 \%$. All subjects exercised to a symptom limited maximum or until they reached theoretical submaximal heart rate.

\section{ECHOCARDIOGRAPHIC MEASUREMENTS}

All the CHF, disuse atrophy patients, and control subjects had cross sectional echocardiography and colour Doppler. Ejection fraction, left ventricle end diastolic diameter (LVEDD), left ventricle end systolic diameter (LVESD), and A wave/E wave ratio were calculated with an apical four chamber approach. Ejection fraction was calculated with the modified Simpson method.

New York Heart Association (NYHA) class was assessed in all the patients.

DIURETIC CONSUMPTION

Patients were divided into five classes according to diuretic consumption. Class 1 was no diuretic, class 2,20 to $40 \mathrm{mg}$ of frusemide or a thiazide diuretic a day, class $3 \geqslant 40 \mathrm{mg}$ frusemide, class $4 \geqslant 80 \mathrm{mg}$, class 5 $\geqslant 120 \mathrm{mg}^{10}$

\section{INDEX OF MUSCLE ATROPHY}

We used the gastrocnemius cross sectional area to body mass index (BMI) ratio to assess the degree of muscle atrophy. Cross sectional area was measured with a computerised tomography scan. Transverse images were obtained in the same location on each leg one third distal to the popliteal space.

ELECTROPHORETIC SEPARATION OF MHC

The method is an improvement of that developed by Carraro et al. ${ }^{1}$ Biopsies were solubilised in $100-200 \mu \mathrm{l}$ of $2-3 \%$ sodium dodecyl sulphate (SDS), $10 \%$ glycerol, $0.5 \% 2$-mercaptoethanol, and $62.5 \mathrm{mM}$ Tris- $\mathrm{HCl}$ pH 6.8 and boiled for five min. The running buffer was added to the sample in a ratio of $1: 1$ $\mathrm{vol} / \mathrm{vol}$. Analytical SDS page of MHC was performed on $7 \%$ polyacrylamide slabs, prepared according to Laemmli, ${ }^{12}$ but $37.5 \% \mathrm{vol} / \mathrm{vol}$ glycerol was present in both the separating and the stacking gel. The stacking gel was composed of $37.5 \%$ glycerol, $4 \% \mathrm{~T}$ acrylamide-Bis $(36.5: 1), 12.5 \mathrm{mM}$ Tris- $\mathrm{HCl}(\mathrm{pH} 6.8)$, and $0 \cdot 1 \%$ SDS. The separating gel was composed of $37.5 \%$ glycerol, $7 \% \mathrm{~T}$ acrylamide-Bis $(36.5: 1), 375 \mathrm{mM}$ Tris- $\mathrm{HCl}(\mathrm{pH} 8 \cdot 8)$, and $0 \cdot 1 \%$ SDS. Running buffer was made of 50 $\mathrm{mM}$ Tris, $384 \mathrm{mM}$ glycine, $\mathrm{pH} 8 \cdot 3$, and $0.2 \%$ SDS. Separation of MHC was achieved using constant current at $4 \mathrm{~mA}$ (corresponding to about $40 \mathrm{~V}$ ). After $6-8 \mathrm{~h}$ the running buffer was changed and electrophoresis restarted with the same parameters. After $24 \mathrm{~h}$ the voltage rises to about $130-160 \mathrm{~V}$ and the run is stopped. ${ }^{13}$ Gels containing approximately $0.2 \mu \mathrm{g}$ of protein per band are usually stained with $0.1 \%$ Coomassie brilliant blue in $5 \%$ acetic acid $/ 40 \%$ methanol and destained with $40 \%$ methanol $/ 7 \%$ acetic acid. Some gels with less than $0 \cdot 1 \mu \mathrm{g}$ protein loaded were afterward stained with the silver method. Identification of individual MHCs was performed by immunoblotting the gel bands with a panel of monoclonal antibodies (generous gift of Prof S Schiaffino). ${ }^{13} 14$

\section{ASSESSMENT OF MHC CONTENT}

The percent distribution of $\mathrm{MHC1}, \mathrm{MHC} 2 \mathrm{a}$, and $\mathrm{MHC} 2 \mathrm{~b}$ was determined by densitometric scan of the stained slab gels. A GS300 transmittance reflectance scanning densitometer (Hoefer Scientific Instruments) connected to a McIntosh SE Apple computer was used. Data were processed with a GS370 densitometry software. A linear response is attained on densitometry when $0 \cdot 1-2 \mu \mathrm{g}$ of individual $\mathrm{MHC}$ is analysed. ${ }^{15}$ Quantitative densitometry was performed using internal MHC standards electrophoresed in the same gel. ${ }^{16}$ 


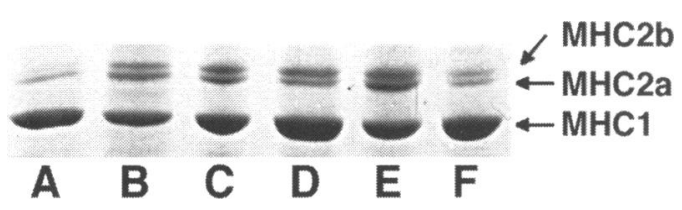

Figure 1 Polyacrylamide SDS slab-gel electrophoresis of myosin heavy chains (MHC). Arrows indicate the three MHC isoforms separated on the basis of their relative mobility: in order from fastest to slowest, $M H C 1$, $M H C 2 a, M H C 2 b$. Lane A: disuse atrophy; lane $B$ : severe $C H F$; lane $C$ : moderate $C H F$; lane D: control; lane $E$ : severe $C H F$; lane $F$ : control.

\section{STATISTICAL ANALYSIS}

Coefficient of variation, Student $t$ test for unpaired data, mean (SD), and linear regression are used where appropriate.

\section{Results}

AGE

Age did not differ significantly in the three groups of patients, being $71 \cdot 2(7 \cdot 6)$ years in the CHF group, $71.0(8 \cdot 1)$ in the disuse atrophy patients, and $55.4(8 \cdot 5)$ in the control subjects.

NYHA CLASS

Of the CHF patients, four were in NYHA class I, four in class II, eight in class III, and three in class IV.

\section{ECHOCARDIOGRAPHIC INDICES}

Ejection fraction was $42 \cdot 5(15 \cdot 2) \%(n=17)$ in CHF patients. This was significantly lower $(P<$ $0.001)$ than in either disuse atrophy or control subjects [59.5 (1.0), $\mathrm{n}=5$, and $60.3(1 \cdot 4), \mathrm{n}$ $=7$, respectively]. There were no significant differences between the two latter groups, neither were there significant differences in LVESD between CHF, disuse atrophy, and control subjects $\left[\begin{array}{lll}38.7 & (13.5) & \mathrm{mm}, 29.0\end{array}\right.$ $(2 \cdot 9) \mathrm{mm}$, and $32.0(1 \cdot 1) \mathrm{mm}$, respectively], although there was a trend in CHF patients for slightly higher values $(P=0 \cdot 1)$. LVEDD values showed a similar trend, being $57 \cdot 8$ $(11.8) \mathrm{mm}$ in CHF, 54.1 (11.2) $\mathrm{mm}$ in disuse atrophy, and $55 \cdot 1(12 \cdot 8) \mathrm{mm}$ in controls.

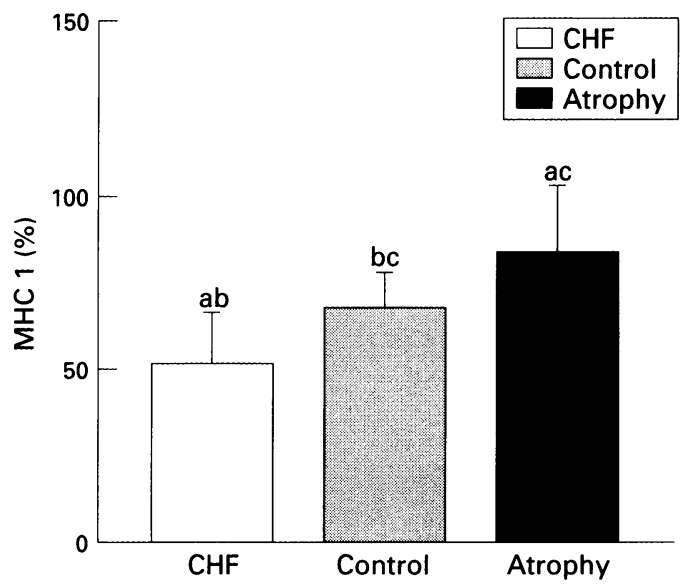

Figure 2 Myosin heavy chain 1 (MCH1) composition in congestive heart failure (CHF), control subjects, and disuse atrophy patients. aa $P<0.01 ; b b P<0.01$; cc $P<0 \cdot 1$.

$\mathrm{A} / \mathrm{E}$ ratio was significantly higher in the seven patients with $\mathrm{CHF}$ and sinus rhythm in whom it could be measured $[1.06(0.31)]$ than in the controls $[0.73(0 \cdot 14)]$ and disuse atrophy patients $[0.76(0 \cdot 18)](\mathrm{P}<0.05$ for both).

\section{DEGREE OF MUSCLE ATROPHY}

Patients with disuse atrophy showed a profound degree of atrophy, with a BMI to gastrocnemius cross sectional area ratio (BMI/CSA) of $0.94(0.39)$. CHF patients showed intermediate values $[2 \cdot 60(1 \cdot 10)]$, and in the control subjects the ratio was $4 \cdot 27(0 \cdot 16)$ $(\mathrm{P}<0.005 \mathrm{CHF} v$ controls; $\mathrm{P}<0.005 \mathrm{CHF} v$ disuse atrophy; $\mathrm{P}<0.0005$ disuse atrophy $v$ controls).

\section{CARDIOTHORACIC RATIO}

Cardiothoracic ratio was $0.56(0.11)$ in $\mathrm{CHF}$ patients, $0.48(0.05)$ in disuse atrophy, and $0 \cdot 40(0 \cdot 10)$ in controls.

\section{DIURETIC CONSUMPTION}

Diuretic consumption score was 1 in seven subjects, 2 in seven, 3 in six, 4 in four, and 5 in two.

NYHA class, age, sex, and myosin heavy chain (MHC) composition in congestive heart failure (CHF), disuse atrophy, and control patients

\begin{tabular}{|c|c|c|c|c|c|c|c|c|c|c|c|c|c|}
\hline \multicolumn{6}{|l|}{$C H F$} & \multicolumn{4}{|c|}{ Disuse atrophy } & \multicolumn{4}{|l|}{ Controls } \\
\hline \multirow[b]{2}{*}{ Disease } & \multirow[b]{2}{*}{$N Y H A$} & \multirow[b]{2}{*}{ Age/sex } & \multicolumn{3}{|c|}{$M H C \%$} & \multirow[b]{2}{*}{ Age/sex } & \multicolumn{3}{|c|}{$M H C \%$} & \multirow[b]{2}{*}{ Age/sex } & \multicolumn{3}{|c|}{$M H C \%$} \\
\hline & & & 1 & $2 a$ & $2 b$ & & 1 & $2 a$ & $2 b$ & & 1 & $2 a$ & $2 b$ \\
\hline DCM & II & $54 / \mathrm{M}$ & 52 & 30 & 18 & $71 / \mathrm{M}$ & 79 & 11 & 10 & $58 / \mathrm{M}$ & 80 & 10 & 10 \\
\hline DCM & II & $73 / F$ & 64 & 23 & 13 & $74 / \mathrm{F}$ & 100 & 0 & 0 & $55 / \mathrm{M}$ & 70 & 30 & 0 \\
\hline $\mathrm{DCM}$ & III & $73 / \mathrm{M}$ & 71 & 8 & 21 & $60 / \mathrm{M}$ & 100 & 0 & 0 & $61 / \mathrm{F}$ & 64 & 22 & 12 \\
\hline HYP & III & $71 / \mathrm{F}$ & 44 & 21 & 35 & $71 / \mathrm{F}$ & 84 & 8 & 7 & $46 / \mathrm{M}$ & 49 & 29 & 22 \\
\hline IHD & III & $69 / \mathrm{M}$ & 48 & 23 & 29 & $79 / \mathrm{M}$ & 59 & 22 & 19 & $42 / \mathrm{M}$ & 65 & 23 & 14 \\
\hline HYP & I & $71 / \mathrm{M}$ & 81 & 10 & 9 & & & & & $61 / \mathrm{F}$ & 71 & 9 & 20 \\
\hline HYP & IV & $84 / \mathrm{M}$ & 28 & 42 & 30 & & & & & $65 / F$ & 77 & 23 & 0 \\
\hline IHD & III & $69 / \mathrm{F}$ & 50 & 21 & 29 & & & & & & & & \\
\hline DCM & I & $65 / \mathrm{M}$ & 64 & 0 & 36 & & & & & & & & \\
\hline IHD & II & $75 / M$ & 46 & 22 & 32 & & & & & & & & \\
\hline DCM & IV & $81 / \mathrm{F}$ & 43 & 51 & 15 & & & & & & & & \\
\hline DCM & IV & $81 / \mathrm{F}$ & 19 & 58 & 23 & & & & & & & & \\
\hline IHD & II & $71 / \mathrm{M}$ & 69 & 16 & 18 & & & & & & & & \\
\hline DCM & III & $74 / \mathrm{F}$ & 43 & 38 & 19 & & & & & & & & \\
\hline DCM & III & $74 / \mathrm{M}$ & 47 & 33 & 20 & & & & & & & & \\
\hline IHD & III & $69 / M$ & 64 & 11 & 25 & & & & & & & & \\
\hline IHD & III & $69 / \mathrm{F}$ & 54 & 16 & 30 & & & & & & & & \\
\hline HYP & I & $56 / \mathrm{F}$ & 64 & 23 & 13 & & & & & & & & \\
\hline DCM & I & $73 / \mathrm{F}$ & 72 & 11 & 17 & & & & & & & & \\
\hline
\end{tabular}

DCM, dilated cardiomyopathy; HYP, hypertensive heart disease; IHD, ischaemic heart disease; NYHA, New York Heart Association functional class. 
Figure 3 Myosin heavy chain $2 a(M H C 2 a)$ composition in congestive heart failure (CHF), control subjects, and disuse atrophy patients. aa $P<$ $0.05 ; b b P=N S$; cc $P<0.05$.

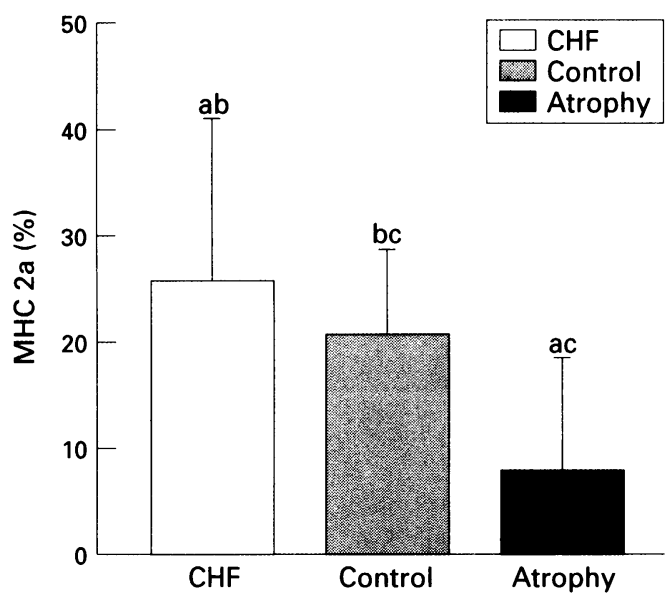

MYOSIN HEAVY CHAIN COMPOSITION

MHC isoforms were separated by SDS-page as described in Methods and presented in fig 1 . In human skeletal muscle three MHC isoforms are usually separated on the basis of their relative mobility, in the order of fastest to slowest, MHC1, MHC2a, MHC2b. Sometimes the 2a band splits allowing the identification of the fast MHC2x component. When such a separation occurs we included the $2 x$ band in the $2 a$ for quantitation. Although the physiological meaning of the $2 x$ is still debated, its function seems similar to that of $2 \mathrm{a}$ and it is therefore assimilable. ${ }^{14}$ MHC composition in CHF, disuse atrophy, and control subjects is summarised in the table. CHF patients showed a significantly lower percentage of MHC1 than control subjects $[51.83(15.04) v 68.0(10.2) \quad \mathrm{P}<0.01]$ and a slightly higher, though not significant, percentage of MHC2a [24.83 (15.01) v 20.86 (8.35), $\mathbf{P}=\mathrm{NS}]$ and MHC2b [23.5 (7.45) $v$ $11 \cdot 14$ (8.71), $P<0 \cdot 01$ ]. Surprisingly, disuse atrophy patients showed a remarkable shift toward the slow isoforms. In fact the percentage of $\mathrm{MHC1}$ was significantly higher [84.50 (17.04)] than that of CHF patients $(P<0.01)$ and showed a trend toward significance when compared to that of control patients $(P<0 \cdot 1)$ (fig 2). On the other hand there was a decrease in both the percentage of MHC2a [8.25 (9.12)] and MHC2b [7.25 (7.92)]. The percentage of the fast oxidative fibres was significantly smaller than in the CHF patients and controls $(\mathrm{P}<$ 0.05 for both) (fig 3). The fast glycolytic myosin percentage was significantly lower than in the CHF patients $(\mathrm{P}<0.001)$ (fig 4$)$.

CORRELATION BETWEEN MHC COMPOSITION AND CLINICAL SEVERITY OF CHF

Clinical indices of the severity of heart failure were correlated with MHC composition in patients with $\mathrm{CHF}$ and controls.

\section{NYHA class}

There was a negative correlation between percentage of MHC1 and NYHA class $(r=0 \cdot 74$, $\mathrm{P}<0.001$ ), and a positive correlation between NYHA class and MHC2a $(r=0.47, \mathrm{P}<0.05)$ and MHC2b $(r=0.55, \mathrm{P}<0.01)$ (fig 5).

Ejection fraction

Ejection fraction correlated positively with

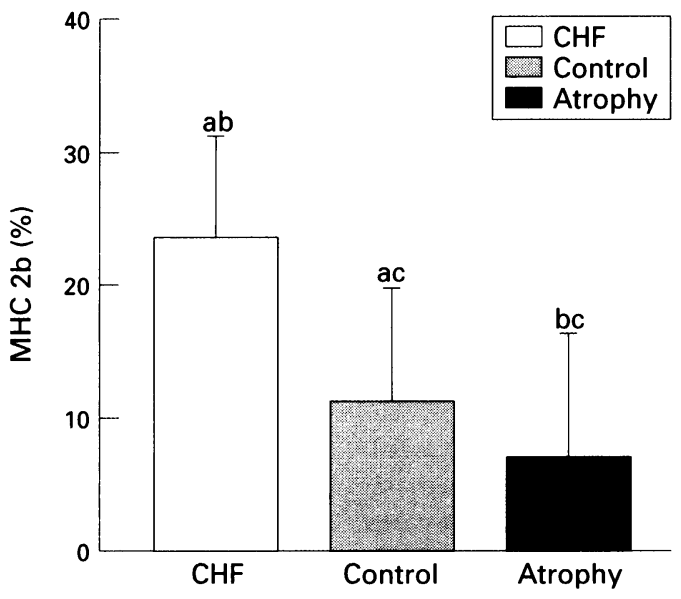

Figure 4 Myosin heavy chain $2 b$ (MHC2b) composition in congestive heart failure (CHF), control subjects, and disuse atrophy patients. aa $P<0.01 ; b b P<0.001$; cc $P=N S$.

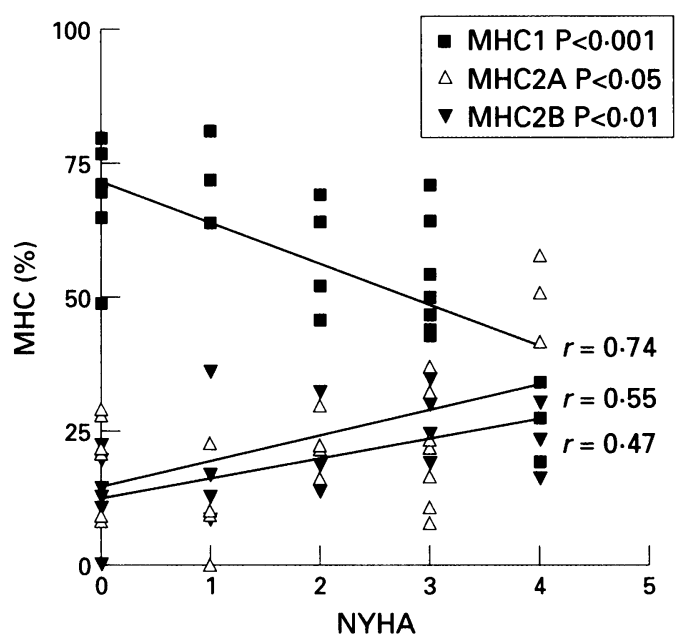

Figure 5 Correlation between the three myosin heavy chain (MHC) isoforms and New York Heart Association (NYHA) class.

MHC1 $(r=0.65, \mathrm{P}<0.001)$ and negatively with MHC2a $(r=-0.75, \quad \mathrm{P}<0.001)$. Although there was a trend for MHC2b to decrease in patients with higher ejection fraction, this did not reach statistical significance ( $r$ $=0 \cdot 26, \mathrm{P}=\mathrm{NS}$ ) (fig 6).

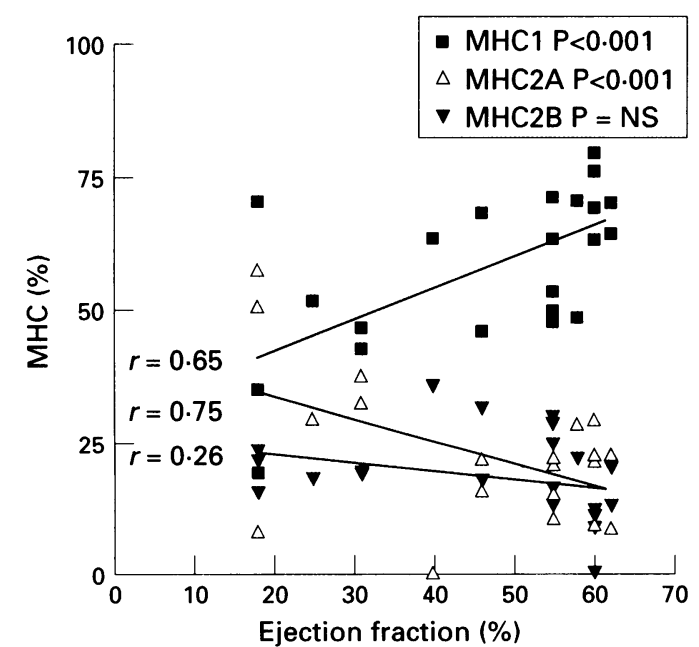

Figure 6 Correlation between the three myosin heavy chain (MHC) isoforms and ejection fraction. 
Figure 7 Correlation between the three myosin heavy chain (MHC) isoforms and diuretic consumption.

Figure 8 Correlation between the three myosin heavy chain (MHC) isoforms and exercise tolerance.
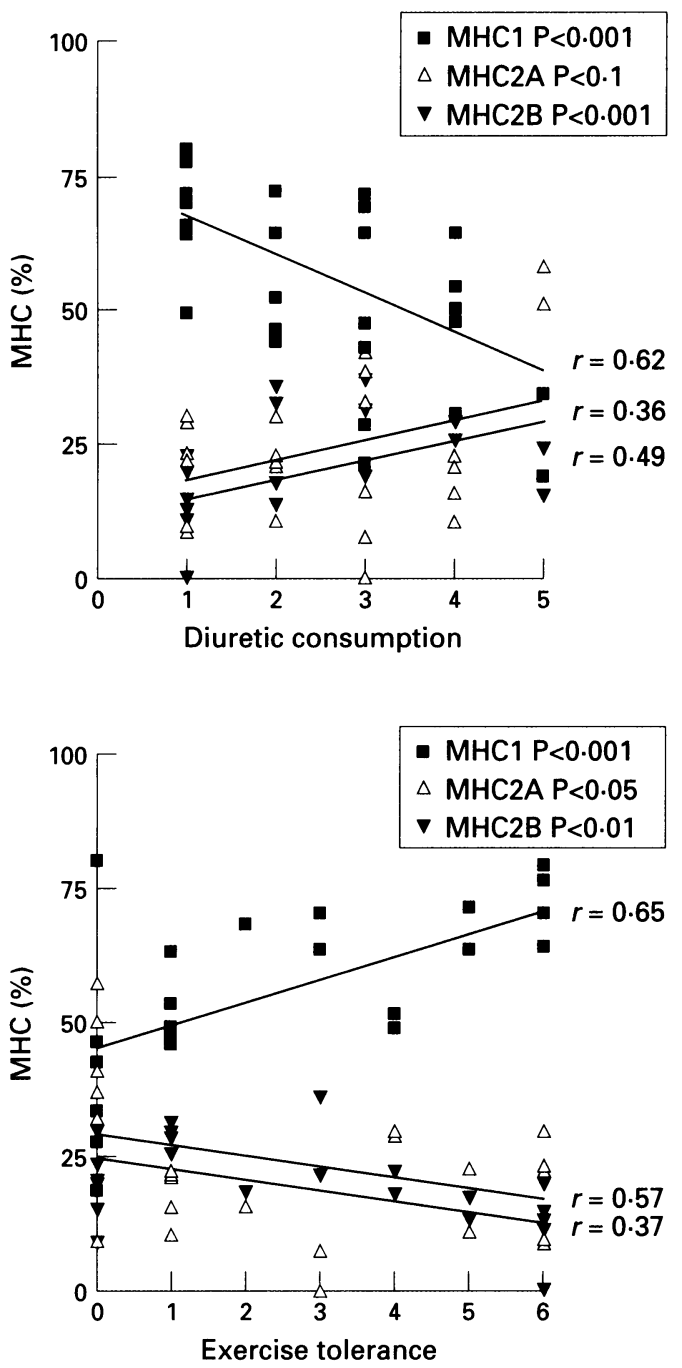

Figure 9 Correlation between the three myosin heavy chain (MHC) isoforms and degree of muscle atrophy (gastrocnemius cross sectional arealbody mass index $(C S A / B M I))$.

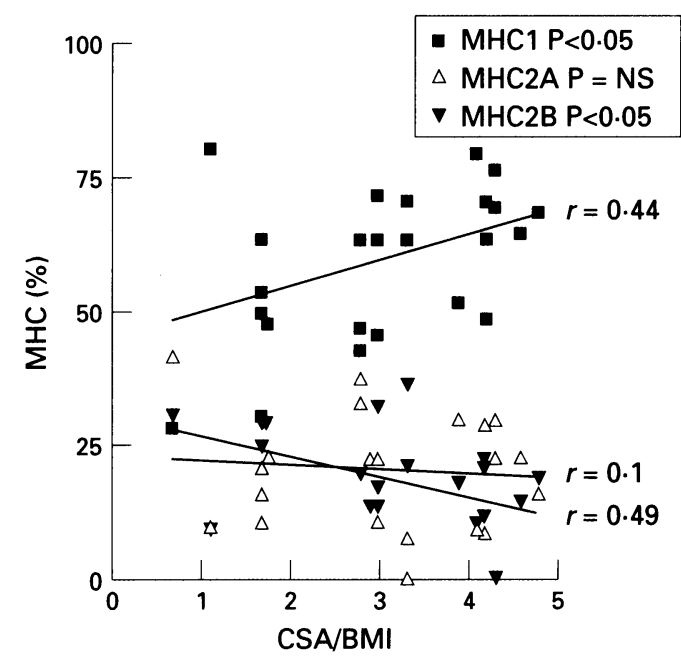

Diuretic consumption

Diuretic consumption score correlated negatively with MHC1 $(r=-0.62, \mathrm{P}<0.001)$ and positively with MHC2a $(r=0.35, \mathrm{P}<0 \cdot 1)$ and MHC $2 \mathrm{~b}(r=0.49, \mathrm{P}<0.001)$ (fig 7$)$.

\section{Exercise test tolerance}

There were significant correlations between steps reached on the treadmill and MHC composition. The correlation was positive for MHC1 $(r=0.65, \mathrm{P}<0.001)$ and negative for MHC2a $(r=-0.37, \mathrm{P}<0.05)$ and MHC $2 \mathrm{~b}(r$ $=-0.57, \mathrm{P}<0.01$ ) (fig 8).

\section{LVESD and LVEDD}

There was no significant correlation between MHC composition and either LVEDD or LVESD, although there was a trend for LVESD to correlate negatively with MHC1.

Degree of muscle atrophy

Combining the data from $\mathrm{CHF}$ and control subjects, there was a significant positive correlation between the BMI/CSA ratio index and MHC1 $(r=0.44, \quad \mathrm{P}<0.05)$. MHC2b was negatively correlated with BMI/CSA $(r=$ $-0.49, P<0.05)$. There was no correlation with $\mathrm{MHC} 2 \mathrm{a}(r=0 \cdot 10, \mathrm{P}=\mathrm{NS})$ (fig 9).

REPRODUCIBILITY OF THE METHOD

Five biopsies were taken from the same subject with CHF and processed separately. Samples from the five different biopsies were loaded on the same slab gel. The coefficient of variation between the five samples was $5 \%$ for $\mathrm{MHC1}$, $5 \%$ for MHC2a, and $7 \%$ for MHC2b. We also loaded on five separate SDS-page samples from one patient. Electrophoreses were carried out on separate days, and the sample- once solubilised in SDS, 2-mercaptoethanol, and Tris$\mathrm{HCl}$-was kept in a fridge at $-10^{\circ} \mathrm{C}$ until the next experiment was done. The coefficient of variation was $4 \%$ for $M H C 1,6 \%$ for $M H C 2 a$, and $4 \%$ for MHC $2 b$.

\section{Discussion}

Our study shows a decrease in the percentage of type I skeletal muscle MHC and an increase in the percentage of type II in patients with $\mathrm{CHF}$ of different aetiologies. The percentage of $\mathrm{MHC1}$ in CHF subjects was $25 \%$ less than that of controls, while the fast glycolytic isoform $2 b$ nearly doubled, being $52 \%$ higher. The shift toward fibres which possess a lower oxidative capacity is consistent with published reports of phosphocreatine depletion, ${ }^{17}$ acidosis, ${ }^{18}$ and enzymatic alterations. ${ }^{19} 20$

Our data are in agreement with those of Lipkin $e t a l^{2}$ who described a decrease in type I fibres and those of Mancini et $\mathrm{al}^{4}$ and Sullivan et $a l^{20}$ who reported an increased percentage of fast twitch IIb fibres and atrophy of type I slow twitch fibres. Similar results have been reported by Sabbah et $a l^{21}$ in dogs with congestive heart failure. These changes have been ascribed to intrinsic skeletal muscle abnormalities ${ }^{22}$ and only in part to muscle underperfusion. ${ }^{1}$ Moreover Wilson et al suggested that exertional fatigue is due to skeletal muscle abnormalities and not to reduced blood flow. ${ }^{23}$ Atrophy due to muscle deconditioning ${ }^{7}$ has been claimed to be partially responsible for these muscle alterations.

Our data do not entirely support the hypothesis that prolonged immobilisation is the cause of changes in MHC composition of skeletal muscle. In fact our patients with disuse atrophy, though there were only five, showed a shift toward the slow MHC1 myosin and thus their behaviour was opposite to CHF patients. On the other hand the degree of muscle atrophy within the control and CHF patients correlated with the progressive decrease in $\mathrm{MHCl}$ and 
increase of MHC2b content. We also found a correlation between MHC composition and indicators of severity of CHF such as NYHA class, exercise tolerance, diuretic consumption, and ejection fraction. It seems that patients with CHF have a specific myopathy, the severity of which is related to that of the heart failure syndrome. It may well be that in these patients the correlation between degree of atrophy and MHC composition is simply the reflection of two phenomena heading in the same direction: (1) progressive muscle deconditioning, which in turn leads to muscle wasting and atrophy without changes in fibre distribution, ${ }^{89}$ and (2) intrinsic changes in skeletal muscle leading to a shift in the contractile protein pattern. This second phenomenon could resemble what occurs in the heart, where adaptive changes in the isozymic composition of the myocardium are observed during the development of both hypertrophy and failure..$^{24}$

The existence of a specific skeletal muscle myopathy with selective type I fibres atrophy has been reported already by Caforio et $a^{26}$ in patients with cardiomyopathies. Changes in skeletal muscle in CHF are very much the same of those observed in the muscle denervation in the rat, where an increased expression of adult fast myosins occurs. ${ }^{27}$ Since the synthesis of adult slow myosins is dependent on the activity of motor innervation, while adult fast myosin is expressed in denervated fibres even though the neuronal influences are removed, ${ }^{28}{ }^{29}$ we cannot exclude a neural contribution to the origin of the myopathy. Coats et al have recently proposed the "ergo- and metabolo-receptors" theory to explain symptoms and muscle wasting in CHF. ${ }^{30}$ Chemically sensitive receptors detect muscle work and metabolism and transmit to the central nervous system stimuli that can drive blood pressure responses and increase sympathetic activity. An increased ergoreceptor activity in patients with CHF might maintain the increased sympathetic outflow, with consequent increased peripheral resistances, decreased perfusion, and further muscle deterioration. Alternatively circulating factors such as increased concentrations of tumour necrosis factor $^{31}$ or metabolic and vascular alterations like insulin resistance ${ }^{32}$ or increased thickness of the endothelial cells ${ }^{33}$ can be invoked as determinants of muscle changes.

The novelty of our study is the application to very small biopsies, and for the first time in cardiology, of a high resolution micromethod that allows separation of the three MHCs isoforms from extremely small tissue samples. The reproducibility of this method is fairly high. Fine needle biopsies are extremely easy to perform and so well tolerated that they do not require any sort of anaesthesia. We had no complications in our series of patients. The technique allows serial biopsy sampling in the same patients, making possible the study of either muscle worsening during the progression of the disease or possible improvements due to different therapies such as training or hormonal treatment that may be able to restore muscle bulk, relieve symptoms, and increase exercise tolerance. ${ }^{34}$ Study of MHC composition may also have the potential to detect early changes in skeletal muscle composition and correlate them with humoral, biochemical, and functional variables.

1 Minotti JR, Christoph I, Oka R, Weiner MW, Welles L, Massie BM. Impaired skeletal muscle function in patients with congestive heart failure. Relationship to systemi exercise performance. f Clin Invest 1991;88:2077-82.

2 Lipkin DP, Jones DA, Round JM, Poole-Wilson PA. Abnormalities of skeletal muscle in patients with chronic heart failure. Int $f$ Cardiol 1988;18:187-95.

3 Minotti JR, Pillay P, Chang L, Wells L, Massie BM. Neurophysiological assessment of skeletal muscle fatigue in patients with congestive heart failure. Circulation 1992; 86:903-8.

4 Mancini DM, Coyle E, Coggan A, Beltz J, Ferraro N, Montain S, et al. Contribution of intrinsic skeletal muscle changes to ${ }^{31} \mathrm{P}$ NMR skeletal muscle metabolic abnormalities in patients with chronic heart failure. Circulation malities in patients

5 Sullivan MJ, Green HJ, Cobb FR. Skeletal muscle biochemistry and histology in ambulatory patients with longterm heart failure. Circulation 1990;81:518-27.

6 Drexler H, Riede U, Muenzel T, Koenig H, Funke E, Just $\mathrm{H}$. Alterations of skeletal muscle in chronic heart failure. Circulation 1992;85:1751-9.

7 Drexler H, Muenzel T, Riede U, Just H. Adaptive changes in the periphery and their therapeutic consequences. $A m \mathcal{F}$ Cardiol 1991;67:29-35C

8 Green HJ, Thomsen JA, Daub BD, Ranney DA. Biochemical and histochemical alterations in skeletal muscle in man during a period of reduced activity. Can $\mathcal{F}$ Physiol Pharmacol 1980;58:1311-6.

9 Patel A, Razzack Z, Dastir D. Disuse atrophy of human skeletal muscle. Arch Neurol 1967;20:413-21.

10 Harding SE, Jones SM, O'Gara P, Del Monte F, Vescovo $\mathrm{G}$, Poole-Wilson PA. Isolated ventricular myocytes from failing and non-failing human heart; the relation of age and clinical status of patients to isoproterenol response. $\mathcal{F}$ Mol Cell Cardiol 1992;24:549-64.

11 Carraro U, Catani C. A sensitive SDS-page method separating myosin heavy chain isoforms of rat skeletal muscles reveals the heterogeneous nature of the embryonic myosin. Biochem Biophys Res Commun 1983;116:793-802.

12 Laemmli UK. Cleavage of structural proteins during the assembly of the head of the bacteriophage T4. Nature 1970;81:518-27.

13 Rossini K, Rizzi C, Sandri M, Bruson A, Carraro U. Highresolution sodium dodecyl sulfate-polyacrylamide gel electrophoresis and immunochemical identification of the $2 \mathrm{X}$ and embryonic myosin heavy chains in complex the $2 \mathrm{X}$ and embryonic myosin heavy chains in complex
mixtures of isomyosins. Electrophoresis 1995;16:101-4.

14 Schiaffino S, Reggiani C. Myosin heavy chain isoforms in mammalian skeletal muscle. $f$ Appl Physiol 1994;77: 493-501.

15 Sandri M, Rizzi C, Catani C, Carraro U. Small and large scale preparative purification of myosin light and heavy chains by selective KDS precipitation of myosin subunits: yield by SDS page and quantitative orthogonal densitometry. Basic Appl Myology 1992;2:107-14.

16 Jakubiec-Puka A, Catani C, Carraro U. Myosin heavychain composition in striated muscle after tenotomy. Biochem f 1992;282:237-42.

17 Massie BM, Conway M, Yonge R, Frostick S, Sleight P, Ledingham $\mathrm{J}$, et al. ${ }^{31} \mathrm{P}$ nuclear magnetic resonance evidence of abnormal skeletal muscle metabolism in patients with congestive heart failure. Am $₹$ Cardiol 1987;60: with conge $309-15$.

18 Massie BM, Conway M, Yonge R, Frostick S, Ledingham J, Sleight $\mathrm{P}$, et al. Skeletal muscle metabolism in patients with congestive heart failure: relation to clinical severity and blood flow. Circulation 1987;76:1009-19.

19 Sullivan MJ, Green HJ, Cobb FR. Altered skeletal muscle metabolic response to exercise in chronic heart failure. Relation to skeletal muscle aerobic enzyme activity. Circulation 1991;84:1597-607.

20 Sullivan MJ, Green HJ, Cobbe FR. Skeletal muscle biochemistry and histology in ambulatory patients with long term heart failure. Circulation 1990;81:518-27.

21 Sabbah HN, Hansen-Smith F, Sharow VG, Kono T, Lesch $M$, Gengo PJ, et al. Decreased proportion of type I myofibres in skeletal muscle of dogs with chronic heart failure. Circulation 1993;87:1729-37.

22 Drexler H. Skeletal muscle failure in heart failure. Circulation 1992;85:1621-3.

23 Wilson JR, Mancini DM, Dunkman WB. Exertional fatigue due to skeletal muscle dysfunction in patients fatigue due to skeletal muscle dysfunction
with heart failure. Circulation 1993;87:470-5.

24 Vescovo G, Harding SE, Jones SM, Dalla Libera L, Pessina AC, Poole-Wilson PA. Comparison between isomyosin AC, Poole-Wilson PA. Comparison between isomyosin pattern and contractility of right ventricular myocytes
isolated from rats with right cardiac hypertrophy. Basic isolated from rats with right

25 Vescovo G, Jones SM, Harding SE, Poole-Wilson PA. Isoproterenol sensitivity of isolated cardiac myocytes from rats with monocrotaline-induced right-sided hypertrophy and heart failure. $7 \mathrm{Mol}$ Cell Cardiol 1989;21: 1047-61.

26 Caforio ALP, Rossi B, Risolti R, Siciliano G, Marchetti A, Agnelli C, et al. Type I fibre abnormalities in skeletal 
muscle of patients with hypetrophic and dilated cardiomyopathy. Evidence for a subclinical myogenic myopathy. F Am Coll Cardiol 1989;14:1464-73. 27 Carraro U, Morale D, Mussini I, Lucke S, Cantini M, Betto R. Chronic denervation of rat hemidiaphragm maintenance of fiber heterogeneity with associated increasing uniformity of myosin isoforms. F Cell Bio 88 Carraro $100: 161-74$

Carraro U, Dalla Libera L, Catani C. Myosin light and heavy chains in muscle regenerating in absence of the nerve: transient appearance of embryonic light chain. Exp Neurol 1982;5:515-24.

29 Butler-Browne GS, Bugaisky LB, Cuenoud S, Schwartz K, Whalen RG. Denervation of newborn rat muscles does not block the appearance of adult fast myosin heavy chain. Nature 1982;299:830-3

30 Coats AJS, Clark AL, Piepoli M, Volterrani M, Poole-
Wilson PA. Symptoms and quality of life in heart failure. The muscle hypothesis. Br Heart ₹ 1994;72:36-9.

31 McMurray J, Abdullah I, Dargie HJ, Shapiro D. Increased concentrations of tumour necrosis factor in "cachectic" patients with severe chronic heart failure. Br Heart $f$ 1991;66:356-8.

32 Swan JW, Walton C, Godsland IF, Clark AL, Coats AJS. Insulin resistance in chronic heart failure. Eur Heart $\dot{f}$ 1994;15:1528-32.

33 Lindsay DC, Anand IS, Bennett JG, Pepper JR, Yacoub MH, Rothery SM et al. Ultrastructural analysis of skeletal muscle microvascular dimensions and basement thickness in chronic heart failure. Eur Heart $f$ 1994;15: $1470-6$

34 Coats AJS, Adamopulos S, Meyer T, Conway J, Sleight P. Physical training in chronic heart failure. Lancet 1990; 335:63-6. 